\author{
Roberto José Moreira \\ PhD em Economia. Professor \\ Adjunto IV da UFRRJ, ICHS, \\ Curso de Pós-graduação em \\ Desenvolvimento, Agricultura e \\ Sociedade, Área Sociedade e \\ Agricultura.
}

\title{
Agricultura Familiar e Sustentabilidade: Valorização e Desvalorização Econômica e Cultural das Técnicas
}

\section{1 - Introdução}

Estaremos neste ensaio analisando as mudanças tecnológicas associadas à agricultura familiar e à questão da sustentabilidade ambiental, em suas facetas econômicas e culturais. A nosso ver a questão da sustentabilidade ambiental recoloca a questão do uso e da propriedade da terra e do meio ambiente natural no capitalismo. No item 1, estaremos problematizando a questão da mudança tecnológica no capitalismo entendendoa como um campo de disputa que envolve um processo de valorização e desvalorização econômica (1.1) e um processo de valorização e desvalorização cultural (1.2) das formas sociais da agricultura familiar. Estas formas sociais são aqui compreendidas como proprietários-trabalhadores ou trabalha- dores por conta própria ${ }^{1}$. No item 2 estaremos examinando a questão da sustentabilidade entendendo-a como um processo de mudança tecnológica que envolve a apropriação privada dos recursos ambientais (terra, biodiversidade e condições climáticas) e como um processo de apropriação do saber. Estaremos polemizando a noção, hoje já difundida, de que a sustentabilidade ambiental tende a revalorizar o saber e o fazer "camponeses”, garantindo às formas sociais da agricultura familiar melhores condições na competição e melhores condições de vida. Estaremos formulando o argumento de que o proprietário-trabalhador (a agricultura familiar) na competição intercapitalista contemporânea tem espaços restringidos de progresso técnico e de valorização econômica e cultural. No ítem 3 es- taremos finalizando nossa argumentação refletindo sobre aspectos de um possível padrão de sustentabilidade aplicado à agricultura familiar na ordem capitalista.

A nosso ver, a mudança tecnológica, enquanto um processo social, vai assumir uma faceta econômica e uma faceta cultural de valorização de determinadas técnicas e determinados conhecimentos, bem como, de desvalorização de outras técnicas e dos saberes a elas associados. Do ponto de vista sócio-cultural e ideológico, estes processos estão associados à valorização das formas sociais que criam ou que se adequam às técnicas valorizadas e que passam a ser tratadas como "modernas" e "avançadas" 2 . As noções de "moderno" e "atrasado" sofrem portanto um processo ideológico de atualização

- ${ }^{2}$ Isto tanto é válido quando se visualiza momentos históricos de valorização das formas empresariais

- vis a vis às formas não empresariais; quanto aos que valorizam formas empresariais de grandes capitais vis a vis aos pequenos capitais. Na atualidade, por exemplo, visualizamos o embate valora- 


\section{Roberto José Moreira}

que contem aspectos econômicos e culturais.

Nossa perspectiva de análise visa abordar estes aspectos da realidade que se tornam visível em processos de mudança dos padrões tecnológicos ${ }^{3}$ hegemônicos, como aponta hoje a questão do "desenvolvimento sustentável”, bem como, contribuir para o entendimento da complexidade social que envolve a agricultura familiar neste final de século.

Os macroprocessos sociais em curso apontam para a configuração de uma nova ordem capitalista internacional ${ }^{4}$. A sustentabilidade associada ao contexto das revoluções tecnológicas da comunicação, da engenharia genética ${ }^{5}$ e da mercantilização do subjetivo deixam visível a importância da ques- tão da apropriação privada sobre o conhecimento ${ }^{6}$.

A sustentabilidade, associada a estas transformações parece apontar para a configuração de um novo padrão tecnológico, que daria a conformação de um capitalismo ecológico, capaz de incorporar os constrangimentos ecológicos à lógica social do capitalismo.

As questões contemporâneas associadas à ecologia e ao meio ambiente certamente estão indicando processos de revalorização da natureza, e da propriedade privada a ela associada ${ }^{7}$. Neste sentido, a nova ordem capitalista, naquilo que se refere à agricultura, pode abrir espaço para uma revalorização do saber e do fazer "camponeses" 8 , o que recoloca a questão da apropriação capitalista dos frutos deste conhecimento. Serão os setores da agricultura familiar os beneficiados por uma reconversão das técnicas no sentido da sustentabilidade social?

\section{2 - Campos de Disputa e a Questão da Tecnologia}

Em outro ensaio ${ }^{9}$ estivemos enfocando a sociabilidade mercantil das formas sociais da agricultura familiar na competição intercapitalista. Procuramos então distinguir espaço social de integração de formas sociais de integração. Enquanto aquele espaço se referia à noção de pequeno patrimônio produtivo e à figura social do proprietário-trabalhador ${ }^{10}$, que também visualizamos como um trabalhador por conta própria, es-

- tivo do toyotismo vis a vis ao fordismo, no interior das formas sociais dos grandes capitais. A ideologia

- difusionista da modernização, que inspirou as atividades da extensão rural nas décadas dos anos 50,

- 60 e 70 no Brasil é um exemplo deste processo.

- ${ }^{3}$ Nos inspira as noções de mudanças paradigmáticas da cultura e da ciência de KUHN (1989) e de

- CAPRA (1982), aqui referenciadas às mudanças dos padrões tecnológicos.

- ${ }^{4}$ Veja MOREIRA (1993), onde examino alguns significados da Eco-92.

- ${ }^{5}$ Esta vertente da tecnologia se desdobra nas questões dos genomas e dos direitos sobre a biotecno- logia

- ${ }^{6}$ Esta questão é abordada em nossa discussão sobre a renda diferencial I em MOREIRA (1995 a)

- ${ }^{7}$ Para uma aproximação desta questão veja MOREIRA (1995 a) onde resignifico a renda da terra - como renda da natureza. Esta reinterpretação questiona a noção de que a fertilidade e a localização - são atributos da natureza e não do fazer social associado ao conhecimento da fertilidade e do signi- ficado social da localização frente aos mercados. Associo a renda da terra à apropriação do conheci- mento que se tem sobre o uso da natureza, presente e futuro. Esta questão também da luz a uma nova elaboração da economia: a economia ecológica, que envolve entre outras questões a elaboração e validação de critérios de medição do valor da natureza. Como capital-dinheiro imobilizado em terras, a terra vai funcionar como reserva de valor, entrando ainda na disputa intercapitalista pela apropriação do excedente econômico, como ativo financeiro e como garantia de acesso a novas po- tencialidades e usos da terra, abertos pelo avanço do conhecimento, das tecnologias e a formação de expectativas com relação ao futuro.

- ${ }^{8}$ Aqui compreendidos como o conhecimento e técnicas associadas à agricultura familiar e à cultura - camponesa.

- ${ }^{10}$ Nesta perspectiva, a posição econômica do pequeno patrimônio produtivo na competição está - associada com o espaço social do proprietário-trabalhador na integração. Ver também MOREIRA

- (1981) e (1979), onde exploramos o espaço da pequena produção no capitalismo e tecemos consi-

- derações sobre campesinato e produção de valor. 
tas formas se referiam às especificidades da integração e à diferenciação interna ${ }^{11}$.

Nossa concepção analítica visa reconhecer a pequena agricultura familiar como sujeita aos desdobramentos da ordem competitiva dominante, campo analítico onde operam: a dinâmica do capital, o movimento da competição intercapitalista, o movimento dos preços relativos, as diferentes formas de capital, a distribuição dos capitais e os rendimentos: lucro, salário, juros e renda da terra.

Em um contexto histórico de generalização da produção de mercadorias, o conhecimento de como opera a competição intercapitalista implica em reconhecer a questão do poder de mercado de diferentes patrimônios produtivos, conforme aparece nas teorias dos preços de monopólio e oligopólio, ou seja, em mercados imperfeitos ${ }^{12}$. Argumentava então que na competição intercapitalista não se co- loca apenas uma questão de eficiência na produção, seja ela técnica ou organizacional. Conta a posição inicial deste patrimônio produtivo nos mercados onde atua, ou seja, a distribuição originária da terra e dos meios de produção, que constituem historicamente os diferentes patrimônios ${ }^{13}$.

A entrada do capital imobilizado - o patrimônio produtivo - na cena analítica permitiu-nos estabelecer uma analogia para a compreensão da propriedade da terra como patrimônio produtivo e como equivalente de capital: não apenas na esfera da distribuição de valor mas também na produção. A esta compreensão denominei de processo de territorialização do capital ${ }^{14}$.

$\mathrm{Na}$ esfera da competição intercapitalista a imobilização de capital dinheiro em terras está associada a outros processos que não os diretamente ligados à produção agrícola. Não é só um processo de valorização das terras produtivas,mas também a valorização das terras improdutivas que está em jogo.

Neste sentido, procurei ressaltar uma das especificidades da mercadoria "terra" frente a outras mercadorias. Um estoque de terras apresenta uma possibilidade de uso bastante flexível. A flexibilidade da utilidade das terras envolve não só uma flexibilidade na produção de diversas mercadorias agropecuárias, bem como uma flexibilidade de utilização não propriamente agrícola: usos urbanos, mineração, energia elétrica, lazer, turismo e, futuramente, recursos da biodiversidade. Neste sentido, podemos dizer que a terra tem a possibilidade de objetivar diversos usos presentes e futuros, respondendo à formação de expectativas sobre o futuro. Esta flexibilização dos usos da terra imprime ao capital imobilizado em terras uma particularidade frente ao capital industrial, cuja composição técnica visa a produção

- ${ }^{11}$ Os estudos referem-se a estes aspectos como: "camponeses" ricos, médios e pobres; integrados e

- não integrados; de subsistência e mercantil; ou ainda, identificam outras especificidades como: agri-

- cultor "profissional"; em tempo parcial; com pluriatividade; e com dualidade rural-urbana.

- ${ }^{12}$ Veja MOREIRA (1995 b) para detalhes da argumentação. A consideração dos elementos da com- petição que estão associados ao volume do capital imobilizado, mas não consumido, e seu tempo de - rotação associado à obsolescência tecnológica, são essenciais para a compreensão do poder de mer- cado e do volume mínimo de capital necessário para entrar em uma dada esfera de produção. Para - os psdrões de concorrência e as barreira à entrada em estruturas oligopolizadas veja POSSAS (1985).

- ${ }^{13}$ Pressupor uma iqualdade inicial entre os capitais produtivos é desconhecer, não só, as especificidades originárias da formação social capitalista, no que se refere a distribuição da propriedade e uso - destes recursos produtivos, mas também, os processos de concentração e centralização próprios da - dinâmica capitalista. Neste sentido, a competição não pode ser considerada, nem em sua origem, nem em sua atualidade como uma competição entre iquais.

- ${ }^{14}$ Nossas discussões sobre a produção e apropriação do conhecimento e a renda da natureza diferem

- da perspectiva marxista e ricardiana. Em Marx e Ricardo, em não claramente em Smith, a proprie-

- dade da terra é tomada como um elemento apenas da distribuição de valores. Considero os recursos

- naturais como componentes do processo produtivo, não como um atributo da natureza mas como

- um componente social do conhecimento sobre estes recursos e seus usos presentes e futuros. No

- sentido capitalista, podemos dizer que a imobilização do capital em terras, produtivas ou improdu-

- tivas, significa a territorialização do capital, e não como algo estranho ao capitalismo, mas próprio

- dele Para detalhes veja (MOREIRA: 1995 a). 
de uma mercadoria determina$\mathrm{da}$, um determinado valor de uso.

Compreendemos a questão da técnica como parte componente do próprio processo social de construção do conhecimento. Saber e fazer são aspectos de um mesmo processo. A construção social da realidade configura-se em um processo dialético de exteriorização, objetivação e interiorização das relações sociais ${ }^{15}$.

A despeito da existência da multiplicidade e pluralidade de conhecimento no interior das sociedades complexas, na ordem capitalista competitiva o conhecimento valorizado - e portanto portador dos elementos da legitimação capitalista - é aquele que se materializa na tecnologia aplicada aos processos sociais hegemônicos.

Quando pensamos na conexão entre as tecnologias valorizadas aquelas pertencentes ao padrão tecnológico em vigor - e as formas sociais que as utilizam, é possível identificar uma correlação entre este padrão tecnológico dominante (ou hegemônico) e as formas sociais de organização da produção e dos serviços também valorizadas, cultural e ideologicamente ${ }^{16}$.

Os setores economicamente modernos são, de forma subjacente, pensados como formas sociais avançadas e superiores. As técnicas tradicionais, economicamente atrasadas ou não competitivas, são visualizadas como formas sociais atrasadas e inferiores.

Visualizamos assim que o processo de mudança tecnológica, em termos de padrão hegemônico ou ainda em termos de revolução tecnológica, envolve um embate de forças em disputa. Estas forças expressam-se no econômico e no cultural e envolvem um duplo processo de apropriação econômica e ideológica. Aquela se dá na disputa no campo econômico e esta se dá na disputa pela identificação com os valores sociais do progresso, do moderno e do avançado.

Nossa contribuição procura visualizar estes dois campos de disputa, o econômico e o cultural, como aspectos de um mesmo processo de mudança.

A faceta econômica de análise mais desenvolvida pela ciência econômica, vai identificar, segundo o grau de lucratividade, as técnicas com vantagens competitivas. Estas técnicas seriam aquelas valorizadas pelo mercado. Nesta esfera de análise, o processo permitiria identificar as técnicas valorizadas economicamente por seu maior grau de lucratividade e sua contraface seria a desvalorização das técnicas menos lucrativas, em um duplo processo de valorização e desvalorização econômica das técnicas: este é o campo de disputa mercantil intercapitalista.

Sua análise na esfera da agricultura familiar implica identificar e analisar a capacidade competitiva da agricultura familiar na ordem competitiva capitalista contemporânea, em contexto de mercados imperfeitos. A viabilidade destas formas de organização da agricultura depende assim de sua inserção na competição intercapitalista.

A faceta cultural da análise, mais desenvolvida pela antropologia, sociologia e história, vai procurar enfatizar o embate cultural entre os valores "modernos" e "atrasados" e/ou "urbanos" e "rurais". Nesta esfera de análise o processo permitiria identificar um campo de disputa político-ideológico onde determinados elementos da cultura são valorizados e outros desvalorizados.

\section{1 - A desvalorização econômi- ca da agricultura familiar}

Em outros contextos ${ }^{17}$, venho elaborando uma perspectiva de interpretação da pequena produção no contexto da dinâmica do capital. Nesta perspectiva, o espaço social da pequena produção de valores mostra-se como um espaço social flexível e mutante, viabili-

- ${ }^{15}$ Veja BERGER e LUCKMANN (1990)

- ${ }^{16}$ Não nos parece outra a correlação entre os setores modernos e atrasados, que a literatura econô-

- mica e política da modernização explicita.

- ${ }^{17}$ Ver MOREIRA (1979), (1981), (1994) e (1995). 
zando formas de integração diferenciadas.

Um indicador destas condições mutantes é o montante mínimo de capital dinheiro que se torna necessário para que um possuidor de mercadoria possa funcionar como capitalista: como a personificação do capital em seu processo de valorização, como uma unidade patronal. No caso da agricultura o montante mínimo de capital dinheiro para funcionar como unidade patronal - como uma pequena empresa - inclui o acesso aos meios de produção, à terra, seja por compra ou arrendamento, e à força de trabalho, incluindo seus respectivos custos sociais ${ }^{18}$.

As exigências da dinâmica competitiva colocadas em diferentes conjunturas bem como a adoção de novos padrões tecnológicos podem afetar as exigências sobre este montante mínimo, elevando-o. Estes processos provocam uma mudança na posição relativa destes capitalistas na esfera da competição, afetando suas condições de lucratividade, reduzindo ou até eliminando a possibilidade de apropriarem-se de valor excedente.

Do ponto de vista técnico, estes processos são visualizados como situações de ineficiência e de atraso tecnológico. Manter-se competitivo no processo de acumulação significa mudar as condições técnicas de produção e acompanhar a elevação deste montante mínimo. Podemos, portanto, visualizar que sobre o conjunto dos pequenos capitalistas paira um campo de força que os empurra para uma inviabilidade econômica competitiva e para a perda da condição de capitalista, mesmo que menores. É um setor de operação de alto risco do ponto de vista empresarial, com baixíssima lucratividade e freqüentes falências ${ }^{19}$.

Tenho ressaltado que na dinâmica intercapitalista, estes processos, no entanto, não implicam necessariamente na perda da propriedade de meios de produção e de terra, mas sim na perda da condição de comando sobre a força de trabalho alheia, na impossibilidade de uso exclusivo do trabalho assalariado e do cumprimento dos encargos sociais e trabalhistas a ele associado. Nos casos e situações onde a perda da propriedade não se realiza, estes proprietários e suas famílias, pressionados ao trabalho produtivo, transformam-se em proprietários-trabalhadores, que também estamos nomeando de trabalhador por conta própria, seja familiar ou não ${ }^{20}$.

O que torna-se relevante aqui é que para este trabalhador a propriedade de meios de produção tornase um requisito fundamental ao exercício do próprio trabalho ${ }^{21}$.

Este é o campo de atuação que o processo de valorização do capital reserva à produção organizada de forma familiar, em suas facetas industrial, comercial e agrícola. A impossibilidade de captação de lucros como norma de operação deste setor proprietário-trabalhador implica reconhecer, teoricamente, a operação de uma subordinação indireta de seu trabalho ao capital22.

Este é o espaço econômico mutante e flexível - da integração social da agricultura familiar com base no trabalho próprio.

Apesar da diversidade de formas

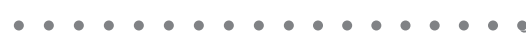

- ${ }^{18}$ Impostos, registros, custos previdenciários e trabalhistas, etc.

${ }^{19}$ Veja STEINDL (1990: 109-114).

${ }^{20}$ Veja MOREIRA (1981 e 1995)

- ${ }^{21}$ Este ser social misto de proprietário e trabalhador, que parecia ser realidade apenas nas formas sociais da agricultura familiar com trabalho próprio, torna-se presente e evidente tanto na indústria, quanto nos serviços. No capitalismo contemporâneo as situações de integração econômica vivênciadas por estas formas sociais não se faz, via de regra, por situações de assalariamento. Aparecem aqui nos contratos de serviços e de produções parciais e especificadas; próprias das noções atuais de terceirização, parcerias e flexibilização produtivas das grandes empresas, bem como, na expansão dos setores informais e dos ditos microempresários.

- ${ }^{22}$ Distinta da subordinação direta, que, em Marx, está referida às formas sociais assalariadas e aos - conceitos de mais-valias absoluta e relativa. Para subordinação indireta, veja SILVA (1977) e MO- REIRA (1979 e 1981). 


\section{Roberto José Moreira}

sociais que estas figuras de proprietário-trabalhador e proprietáriotrabalhador familiar podem assumir na ordem competitiva, sua integração social requer que, do ponto de vista econômico, esteja disposto a abrir mão da lucratividade devida à propriedade que tem sobre meios de produção, operando com lucro-zero e, no caso da agricultura, com renda da terra-zero. A literatura que trata da questão é farta em identificar que parte significativa da agricultura familiar consegue reter apenas uma parcela do valor agregado e que esta parcela corresponde à "remuneração" da força de trabalho familiar ou aos "meios de subsistência" da família.

No caso da agricultura, a estes requisitos adicionam-se as questões da necessidade de terra própria e de uso do trabalho familiar. A operação das relações de trabalho passa da esfera do mercado para a esfera da família, onde operam os valores simbólicos de poder, de mando e de distribuição de valores da organização familiar ${ }^{23}$.

Uma outra forma de pensar/visualizar estes processos pode ser buscada pela análise do processo de desvalorização do capital fixo, associado ao processo de obsolescência tecnológica. Neste processo, os instrumentos de trabalho perdem gradativamente o seu valor de troca, deixando assim de funcionar como capita ${ }^{24}$. A contraface da obsolescência é a inovação tecnológica. Os instrumentos obsoletos, no entanto, não perdem todo o seu valor de uso. Perdem a sua utilidade na ordem capitalista onde estão inseridos e onde opera um determinado padrão de competição intercapitalista. Neste contexto específico perdem sua utilidade como fonte de captação da taxa de lucro que aí vigora.

A aceleração da obsolescência tecnológica no capitalismo monopolista leva à desvalorização do capital produtivo imobilizado, fazendo com que, nesse processo, parte do capital social produtivo deixe de funcionar como capital, em um processo que alguns autores têm denominados de queima ou sucateamento do capital industrial.

Cabe aqui fazer um refinamento desta análise, compreendendo a valorização das terras como um processo de elevação de seus preços. Esta apropriação só se dá diretamente no momento da venda das terras. Este processo social valoriza as terras em geral, sejam elas de grandes ou de pequenos proprietários. A nível social, a territorialização do capital expressa um processo de valorização frente a outra formas de capital, em espe- cial frente ao capital industrial. Uma outra questão é a possibilidade dos proprietários de terras produtivas conseguirem captar a renda da terra como componente dos preços dos produtos agrícolas. Aqui opera mais diretamente sua posição nos mercados dos produtos. Neste sentido, ao não conseguirem captar o excedente sobre a forma de renda da terra como um componente dos preços de mercado dos produtos, podemos dizer que a terra, enquanto terra produtiva, é desvalorizada. Este processo assume um caráter individual e está associado ao poder de mercado de cada produtor, seja ele capitalista ou "camponês". Neste sentido, o capital dinheiro imobilizado em terras produtivas tende a ser desvalorizado na competição intercapitalista.

Os processos que tendem a elevar os preços das terras funcionam também elevando o montante mínimo que qualquer possuidor de dinheiro ou mercadorias tem que avançar para que seu trabalho ou seu capital possa funcionar produtivamente na agricultura. Neste sentido, a valorização das terras age no mesmo sentido que age a elevação da composição técnica e orgânica do capital. Amplia-se, dessa forma, o espaço no qual a produção familiar pode vir a funcionar na agricultura.

- ${ }^{23}$ Cumpre notar que a própria dinâmica de operação do trabalho familiar no interior da família - pode mudar. As regras de mando, as formas de decisão, a distribuição interna do trabalho por sexo

- e idade, bem como, o próprio tamanho médio da família e o peso do trabalho fora da unidade fami-

- liar, seja na agricultura ou fora dela. Estes fenômenos, no nível cultural, podem resignificar a pró- pria noção de família.

- ${ }^{24} \mathrm{Na}$ órbita competitiva, funcionar como capital, significa a captação de uma taxa de lucro acima de zero. 
2.2 - A desvalorização ideológico-cultural da agricultura familiar

Com a elevação do volume mínimo de dinheiro ou mercadoria necessário para que um determinado trabalho passado e presente possa funcionar como capital, abrese um espaço que tende a se ampliar. Neste espaço, os meios de produção e a força de trabalho podem funcionar no processo de geração de valor sem no entanto funcionar como capital individual, ou seja, sem se apropriarem de qualquer taxa de lucro.

Ao incorporarem à mercadoria um tempo de trabalho maior que o necessário para a reprodução simples das condições de produção instrumentos de trabalho e força de trabalho - e sem reter o valor correspondente a esse trabalho excedente, que é apropriado no processo de circulação, estes setores estão contribuindo para a expansão da mais-valia social e, conseqüentemente, para a valorização do capital em geral ${ }^{25}$.
Discutindo os erros associados à discussão dos trabalhos produtivos e improdutivos no contexto da economia clássica, Marx vai sugerir, no "Capítulo VI - Inédito", uma esfera de subsunção ideal do trabalho ao capital, exemplificando com o caso do o trabalhador independente (selfemploying labourer). Este, apesar de não subsumido realmente ao modo dominante de produção, seria subsumido idealmente ${ }^{26}$.

Transladando estas considerações de Marx para o caso em análise, julgo relevante fazer uma associação entre a noção de subordinação indireta e esta noção de subsunção ideal para o caso da agricultura familiar no capitalismo.

As noções de subsunção formal e real, associadas aos conceitos de mais-valia absoluta e relativa e às relações do assalariamento, explicitam, em Marx, o campo da análise da subordinação direta do trabalho ao capital, inadequado para a análise da especificidade das formas não-empresariais, como é o caso da agricultura familiar.
A subordinação indireta do trabalho ao capital reflete uma situação mais sutil e obscura. $\mathrm{Na}$ exploração familiar está presente uma situação de autonomia e independência associada ao econômico e ao cultural, que no entanto conforma-se como uma subordinação aos mercados e à cultura dominante.

A dependência e subordinação econômica da agricultura familiar é difusa e mutante. Envolve a operação dos mercados de terra, bens produtivos, trabalho, crédito, bens de consumo e dos mercados dos produtos agrícolas. Esta dependência e subordinação não se refere apenas ao mercado de produtos agrícolas e à competição entre os produtores agrícolas.

A subordinação cultural é também difusa e mutante, como o é todo o campo das significações sociais. Os significados que a cultura dominante atribui às formas sociais da agricultura familiar tornam-se elementos importantes na configuração de suas relações com o conjunto da sociedade ${ }^{27}$. $\mathrm{Na}$ medida em que estas formas soci-

- ${ }^{25}$ É este o sentido geral que vejo na tese de WANDERLEY (1979) quando trata da questão do - camponês como um trabalhador para o capital.

- 26 "Dentro de la producción capitalista ciertas partes de los trabajos que producem mercancías se siguem ejecutando de una manera propia de los modos de producción precedentes, donde la relación entre el capital e el trabajo asalariado aún no existe de hecho, por lo cual de ninguna manera son aplicables las categorías de trabajo produtivo y trabajo improdutivo, características del punto de vista capitalista. En correspondencia con el modo de producción dominante, empero, las relaciones que aún no se han subsumido realmente en aquél, se le subsumen idealmente (idealiter). El trabajador independiente (selfemploying labourer), a modo de ejemplo, es su propio asalariado, sus propios medios de producción se le enfrentan en su imaginación como capital. En su condición de capitalista de sí mismo, se aoto-emplea como asalariado. Semejantes anomalias ofrecem campo propicio a las monsergas en torno al trabajo produtivo y el improdutivo" (MARX: 1975; 82).

${ }^{27}$ No caso brasileiro as figuras sociais regionalizadas do campesinato tradicional, o "caipira”, "caiçara", "tabaréu”, "cabloco", "sitiante", "agregado", "morador de favor", "colonos do sul” estão carregadas de valores culturais e ideológicos da cultura dominante. como são conhecidos em regiões diferentes do país se confundem em alguns casos com o produtor familiar proprietário. 
ais representam situações vivenciais diferentes e estão associadas a elementos culturais e ideológicos regionalizados, podem informar e conformar ações diferenciadas.

As condições de vida e as condições de trabalho dos agricultores familiares podem se representar em significações associadas à classe trabalhadora assalariada. Suas condições de pequeno proprietário de terra, de bens de produção e sua relativa autonomia na organização da produção e do trabalho familiar, em geral, podem se representar em significações associadas a um pequeno patrão, um pequeno capitalista. Neste sentido, a auto-identificação da agricultura familiar como configurando uma situação de pequeno patrão pode ser representada como sendo uma subsunção ideal. Seja em um ou em outro contexto de representações, o agricultor familiar vivencia uma cultura que o concebe como um ser social inferior. Uma inferioridade objetivada historicamente em sua incapacidade de progresso no contexto da acumulação capitalista. Exteriorizada na cultura dominante, esta concepção tende a se interiorizar na psique camponesa, conformando uma subsunção idealizada.
Como elemento da ideologia e da cultura dominantes, esta concepção de inferioridade conforma um campo de lutas, de aspirações e de interesses legitimados, próprios da construção das identidades das formas sociais da agricultura familiar no capitalismo. O campo difuso que envolve a tradição cultural destas formas sociais, a dinâmica da competição intercapitalista e a concepção dominante sobre os agricultores familiares conformam o campo do embate cultural e a própria percepção que estas formas sociais vão tendo de si mesmas.

No processo dialético de interrelações mercantis e culturais da agricultura familiar com a sociedade envolvente, os processos de socialização e individuação vivenciados pelas novas gerações camponesas tornam-se concretamente diferentes daqueles vivenciados por seus ancestrais: tendem também a ser percebidos e vividos como diferentes pelos próprios agricultores familiares ${ }^{28}$. Estes processos configuram a construção social de uma nova realidade ${ }^{29}$ dominante e crescentemente mercantil.

A concepção dominante de inferioridade da agricultura familiar tende a ser o substrato percep- tivo para a formulação de políticas hegemônicas para o setor.

\section{3 - A Sustentabilidade Am- biental: Valorização do Saber e do Patrimônio Produtivo da Agricultura Familiar?}

Em nossa perspectiva de análise, as dinâmicas econômicas, culturais e políticas hegemônicas não determinam rigidamente a agricultura familiar: abre-se um espaço social flexível à reprodução destas formas sociais ${ }^{30}$. Um espaço difuso e mutante, onde o saber e o fazer das formas sociais da agricultura familiar vivenciam o exercício de uma autonomia relativa. Neste espaço são vivenciadas as especificidades das diferenciações regionais e internas e das distintas formas de integração.

Este é o campo da interação social, da busca de identidade, do exercício da intersubjetividade, da luta social e política. É o campo da incerteza e da imprevisibilidade. É também o campo da possibilidade de emergência do novo.

Neste contexto a questão da sustentabilidade coloca uma indagação: qual é o sentido ${ }^{31}$ e a signi-
PARTE I A AGRICULTURA FAMILIAR ENTRE OS NOVOS DESAFIOS DO MUNDO MODERNO

${ }^{28}$ As idéias de um novo camponês ou de um novo campesinato expressas de diversas formas nos estudos e nos debates sobre o assunto indicam a pertinência desta percepção. $\mathrm{O}$ mesmo se pode dizer a respeito das análises sobre às colônias velhas e novas no sul e os processos recentes de integração camponesa à dinâmica agro-industrial.

- ${ }^{29}$ Veja BERGER e LUCKMANN (1990) sobre a importância da linguagem e suas significações como fundamentos do conhecimento na vida cotidiana. A noção de fundo aqui se baseia na relatividade do conhecimento e da realidade e na idéia de que a realidade é socialmente construida.

- ${ }^{30}$ Veja MOREIRA (1981) para a percepção deste espaço à luz da economia política e MOREIRA (1995 b) para a percepção deste espaço na competição intercapitalista.

${ }^{31}$ Toda teorização sobre o social-histórico tem como pano de fundo conceitual da idéia de um sen- 
ficação que se tornarão hegemônicas no tratamento da questão tecnológica da agricultura familiar nas novas ordens capitalistas internacional e nacional?

No Brasil, a formulação da questão da agricultura familiar e a busca de políticas para este setor estão associadas à noção de manutenção: manutenção da família, da propriedade e da cultura "camponesa”. Esta noção cultural-ideológica aparece também associada à noção de agricultura familiar como agricultura de subsistência ${ }^{32}$. A noção de reprodução econômica da pequena agricultura familiar está aqui associada à geração de uma renda suficiente para manter, subsistir. A contemporaneidade ecológica adiciona mais um elemento a esta concepção dominante: gerar uma renda suficiente para manter a família e usar os recursos naturais de forma sustentável ${ }^{33}$.

Esta proposição desvincula da pequena agricultura familiar a idéia de progresso social, de me- lhoria das condições de vida, bem como a possibilidade de reprodução econômica ampliada.

A exclusão social que tem conformado este setor na história brasileira, bloqueando, não só econômicamente mas também cultural e ideologicamente, sua reprodução sócio-cultural ampliada, é assim naturalizada: os processos de exclusão são tomados como naturais, como atributos intrínsecos à "natureza" da agricultura familiar. O processo sócio-histórico de exclusão, ao se objetivar nas instituições sociais, transmuta-se na cultura, na ideologia e na ciência dominantes como uma característica "natural". Garantir a subsistência e a manutenção tornam-se metas das políticas para o setor.

Neste contexto, a análise da pequena agricultura familiar não leva à crítica da ordem social dominante e nem à percepção de que este setor pode representar um setor socialmente excluído do progresso social. O campo de ação política acaba conformando apenas a busca de tecnologias adequadas ${ }^{34}$. Conforma a técnica e a tecnologia como o único campo da ação política.

Esta concepção dominante sobre a agricultura familiar inclui ainda significações para as noções de agricultura, de família, trabalho familiar, unidade de produção e consumo, cultura e de técnicas ditas "camponesas". Em geral, estas noções estão associadas às noções de atraso, de ignorância e de inferioridade, que em última instância acabam por legitimar projetos visando a modernização tecnológica da agricultura familiar, como foi o caso da "revolução verde" dos anos 60 e 70, que conformou o padrão tecnológico hoje dominante nos setores da agricultura familiar "integrada e moderna”.

A valorização cultural dominante de um certo saber técnico próprio à apropriação privada capitalista e a uma maior eficiência competitiva entra em disjunção com a

- tido da história que aquí tomamos em sua significação racional, segundo a qual a história produz - sentido e esse sentido é portador de indicações para a eventual ação dos homens.

- ${ }^{32}$ A noção de subsistência tem sido utilizada indistintamente com diversos significados. Subsistên-

- cia às vezes aparece como um setor da sociedade que produz alimentos para o conjunto social, fala-

- se neste contexto da importância dominante da pequena produção familiar, mesmo quando se reco-

- nhece a presença da grande produção de alimentos. As vezes aparece como uma produção que

- mantém um nível de vida de subsistência, algo associado à noção de salário de subsistência. Está

- formulação pode se aplicar mesmo nos casos de plena mercantilização da reprodução camponesa.

- Aparece ainda como uma produção de subsistência para auto-consumo, onde pressupõe-se uma

- autonomia quase absoluta do campesinato frente a sociedade. Veja MOREIRA (1994 a) onde exa-

- mino a questão da ideologia da subsistência e do trabalho no contexto pós-escravista no Brasil e

- MOREIRA (1994 b) onde discuto estes elementos da ideologia no contexto do desenvolvimento - sustentável.

- ${ }^{33}$ Esta formulação da questão da agricultura familiar e sustentabilidade ambiental carrega uma ver-

- tente conservadora, ao não se constituir como uma crítica ao "status quo" social, e uma vertente

- tecnicista, que ao se encaminhar apenas na busca de tecnologias adequadas a estas formas sociais, pressupõe que o problema é apenas técnico.

- ${ }^{34}$ A própria noção de adequação sugere a postulação de adequação à ordem vigente. Neste sentido,

- não se coloca apenas a questão da conformação sócio-histórica deste setor no que se refere à propri-

- edade da terra e de seu espaço na ordem competitiva capitalista, mas também na cultura dominante. 
tradição cultural da agricultura familiar, seja desvalorizando o saber técnico "camponês" sobre a natureza, seja apropriando-se deste saber.

A questão da adequação de tecnologias não deixa de ser a questão da adequação de um setor tido como inadequado à ordem competitiva, onde as relações sociais são mediadas pelo mercado e pelas mercadorias. Nesta ordem competitiva, a integração da agricultura familiar é a histórica dos processos de mercantilização a que estão sujeitos, cuja plenitude refletiria a completa mercantilização de sua reprodução social. Este espaço plenamente mercantil é o espaço do proprietário-trabalhador no capitalismo.

\section{4 - Finalizando}

A questão da possibilidade de um novo padrão tecnológico com sustentabilidade ambiental para a agricultura familiar implica reconhecer, como procurei até aqui demonstrar, o peso que a dinâmica da competição intercapitalista e os interesses dos grandes capitais, bem como a concepção dominante sobre a agricultura familiar impõem sobre a formulação e implementação das políticas setoriais.

Discutir formas sociais ou tecnologias alternativas que pressu- ponham o status quo social desta dinâmica é reconhecer que estaremos frente a novos processos de integração e exclusão de formas de agricultura familiar com trabalho próprio, sem grandes perspectivas de progresso social para o seu conjunto. Para os setores da agricultura familiar que se integrarem no padrão de sustentabilidade, a perspectiva parece ser a de garantia de subsistência social e emprego para os membros da família, e nem sempre para todos. Esta garantia está associada à manutenção de seu patrimônio produtivo, incluindo a preservação e melhoria das condicões ecossistêmicas. Para as formas excluídas restam o assalariamento a médio e a longo prazo, ou a marginalização social.

Se a vivência da situação de proprietário-trabalhador é estrutural, e não conjuntural, funcionar como agricultor familiar na ordem competitiva é ter que abrir mão da renda da terra e dos lucros35. Nestas situações, o mínimo requerido para a existência destas formas sociais é que a subsistência familiar seja viabilizada e que o patrimônio seja mantido. Se a unidade produtiva da agricultura familiar é totalmente mercantilizada, o excedente de valor retido corresponderia à "remuneração" do trabalho familiar, como as noções de "salário disfarçado", de "camponês, um trabalhador para o capital" e de trabalhador por conta própria procuram indicar.
Neste sentido, a agricultura familiar supriria a sociedade abrangente com alimentos e matérias primas a baixos custos monetários quando comparados aos das formas empresariais, que requerem a apropriação do lucro e da renda da terra.

Em princípio, as tecnologias da biodiversidade parecem apontar para um uso mais intensivo da força de trabalho familiar, bem como para a transformação de resíduos de alguns processos produtivos como insumos de outros processos. A implantação destes procedimentos poderá levar à substituição progressiva dos insumos metal-mecânicos e químicos, o que poderá reduzir os custos monetários da produção agropecuária na medida em que os insumos das técnicas da sustentabilidade estiverem dissociadas dos mercados ${ }^{36}$. Estes processos apontam para uma redução dos custos monetários da produção agropecuária.

A nosso ver, a dinâmica de operação dos mercados (imperfeitos) não garantem que os benefícios destas novas práticas sejam apropriadas pelos agricultores familiares. Ao contrário, esta dinâmica tem garantido uma apropriação externa à agricultura familiar, temse mostrado eficiente na manutenção do "status quo" econômico e social das formas da agricultura familiar.

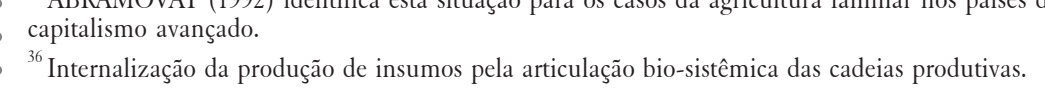


Como estamos procurando argumentar, estes baixos custos não se devem, necessariamente, a uma maior eficiência produtiva ou a uma maior produtividade, como é o caso da agricultura familiar dos países do capitalismo avançado ${ }^{37}$. Para os casos da agricultura familiar não-modernizada, a sua permanência no mercado é atribuída a uma irracionalidade econômica do pequeno, devida a uma suposta cultura "camponesa", que não visa lucro e nem renda da terra. Tanto em um caso, quanto em outro, estes baixos custos se devem também à sua situação de proprietário-trabalhador e de trabalhador por conta própria: "pequenos" na ordem competitiva. Os custos são baixos porque são "pequenos" em mercados imperfeitos ${ }^{38} \mathrm{e}$, como tal, têm um espaço social e econômico de integração restringido.

\section{5 - Bibliografia de Referência}

ABRAMOVAY, Ricardo. (1992) Paradigmas do Capitalismo Agrário em Questão. São Paulo. Rio de Janeiro. Campinas: Hucitec, ANPOCS/Edit. Unicamp.

BERGER, Peter e LUCKMANN, Thomas. (1990) A Construção Social da Realidade. Petrópolis, Vozes.

CAPRA, Fritjof (1982) O Ponto de Mutação. Cultrix, São Paulo
KUHN, Thomas (1989) A Estrutura das Revoluções Científicas. $3^{\mathrm{a}}$ edição. Perspectiva, São Paulo.

LAMARCHE, Hughes (Coord.) (1993) A Agricultura Familiar. Campinas, SP. Editora UNICAMP.

MARX, Karl (1975) El capital. Libro I, Capítulo VI (Inédito). Siglo Veintiuno Editores SA, México.

MOREIRA, Roberto José (1979) "Reflexões sobre o campesinato e a economia política” Texto para discussão interna. Rio de Janeiro: CPDA, EIAP, FGV.

(1981) "A Pequena Produção e a Composição Orgânica do Capital" in Revista de Economia Política, v. 1, nº. 3, pp. 4155, jul/set, 1981.

(1993) "Pensamento

Científico, Cultura e ECO-92: alguns significados da questão ambiental". in Reforma Agrária Revista da Associação Brasileira de Reforma Agrária, Vol. 23, 1, (14-39) jan./abr. e in Universidade e Meio Ambiente, $\mathrm{n}^{\circ} .5$ Revista do NUMA, Universidade Federal do Pará, 1993.

(1994a) "Parceria e os Negócios do Coronel: Trabalho familiar residente e competição no Complexo Rural” UFRRJ/ CPDA/Sociedade e Agricultura. 1993. A ser publicado na $R e-$ vista Universidade Rural, Série Ciências Humanas em 1994. (1994b) "Formação interdisciplinar e desenvolvimento sustentável" in RESUMOS da X Reunião Brasileira de Manejo e Conservação do Solo e da Água. Simpósio: Pequena Propriedade x Desenvolvimento Sustentável. Sociedade Brasileira de Ciência do Solo (SBCS). Florianópolis, SC: 1994, 428p. (pp. 25-32).

MOREIRA, Roberto J. (1995a) "Renda da Natureza e Territorialização do Capital: Reinterpretando a renda da terra na competição intercapitalista" In Estudos em Sociedade e Agricultura, n .4 (89-111); jun. 1995, Rio de Janeiro: UFRRJ/ CPDA/Área Sociedade e Agricultura.

(1995b) "Agricultura Familiar e Assentamentos Rurais: Competitividade, tecnologia e integração social”. Texto apresentado no workshop internacional sobre "O desenvolvimento de uma outra agricultura: acesso à terra e a meios de produção, a questão da fome e a integração social" realizado em Curitiba, em out-nov de 1995. A ser publicado nos ANAIS do Encontro pela Universidade Federal do Paraná.

POSSAS, Mário(1985) Estruturas de Mercado em Oligopólio. São Paulo: Hucitec.

SILVA Sérgio (1977) "Formas de Acumulação e Desenvolvimento do Capitalismo no Campo". In Jaime Pinsky (org). Capital e

- ${ }^{37}$ Ver VEIGA (1991), ABRAMOVAY (1992) e LAMARCHE (1993).

- ${ }^{38}$ Neste sentido, a noção de que os mercados agrícolas são competitivos precisa ser refinada. Pode-se

- afirmar que os mercados poderiam ser considerados competitivos entre os produtores agrícolas.

- Mas, se considerarmos que do outro lado do mercado estão grandes capitais - na esfera financeira,

- na esfera dos insumos industriais para o setor agrícola e na esfera da agroindustria, por exemplo -,

- estes mercados certamente não poderão ser considerados competitivos. FAMILIAR ENTRE OS NOVOS DESAFIOS DO MUNDO MODERNO 


\section{Roberto José Moreira}

22

Trabalho no Campo. São Paulo: Hucitec.

STEINDL, Josef (1990). Pequeno e Grande Capital. São Paulo: Hucitec/Unicamp.

VEIGA, José Eli (1991) O Desenvolvimento Agrícola: uma visão histórica. São Paulo: Editora da USP/Hucitec.

WANDERLEY, Maria Nazareth B.(1979) "O camponês: um trabalhador para o capital”. Campinas: UNICAMP - Grupo de Estudos Agrários (mimeo).

PARTE I A AGRICULTURA FAMILIAR ENTRE OS NOVOS DESA-

FIOS DO MUNDO MODERNO 